\title{
Orodispersible tablets: an overview
}

\begin{abstract}
The oral route is the most widely accepted route. The review deals with overview of orodipersible tablets that includes advantages, disadvantages, properties, methods for its formulation.
\end{abstract}

Keywords: tablets, orodispersible, european pharmacopoeia, mechanical strength, freeze drying
Volume 7 Issue 3 - 2018

\section{Satinder Kakar, Ramandeep Singh, Saurav \\ Kumar}

Department of Pharmacy, Himachal Institute of Pharmacy, India

Correspondence: Satinder Kakar, Department of Pharmacy, Himachal Institute of Pharmacy, India,

Email satinder.kakkar5@gmail.com

Received: February 27, 2018 | Published: June 22, 2018

\section{Introduction}

The oral route of administration is considered as the most widely accepted route because of its convenience of self administration, compactness and easy manufacturing. But the most evident drawback of the commonly used oral dosage forms like tablets and capsules is difficulty in swallowing, leading to patients incompliance particularly in case of pediatric and geriatric patients ${ }^{1}$, but it also applies to people who are ill in bed and to those active working patients who are busy or traveling, especially those who have no access to water ${ }^{2}$.

Oral route is the most preferred route for administration of drugs, because it provides high patient compliance. Dysphagia is commonly found among all age groups. Due to this problem, approximately $50 \%$ of population suffers. The difficulty in swallowing may be due to the taste, size and surface of dosage form. During journey, sometimes water is not easily accessible so a patient feels difficulty in swallowing solid dosage form.

Recently ODT terminology has been approved by United States Pharmacopoeia, British Pharmacopoeia ${ }^{3,4}$ and Centre for Drug Evaluation and Research (CDER). US FDA defined ODT tablets as "A solid dosage form containing medicinal substances which disintegrates rapidly usually within a matter of seconds, when placed upon the tongue". European pharmacopoeia also adopted the term "orodispersible tablet" as a tablet that is to be placed in the mouth where it disperses, rapidly before swallowing despite various terminologies used. ${ }^{5}$

\section{Ideal properties of odts}

a. Require no water for oral administration.

b. Easily dissolve or disperse in saliva within a few seconds.

c. Have a pleasing taste.

d. Leave negligible or no residue in the mouth when administered.

e. Portable and easy to transport.

f. Able to be manufactured in a simple conventional manner within low cost.

g. Be less sensitive to environmental conditions like temperature, humidity etc.

h. Permit the manufacture of tablet using conventional processing. i. It should be compatible with taste masking. ${ }^{6}$

\section{Advantages of orodispersible tablets}

i. Ease of administration to patients who cannot swallow, such as the aged, stroke victims and bedridden patients; patients who should not swallow, such as renal failure patients; and who refuse to swallow, such as paediatrics, geriatric and psychiatric patients.

ii. Improved compliance.

iii. Better Patient's compliance for disabled bedridden patients and for travelling and busy people, who do not have ready access to water.

iv. No water needed.

v. No chewing needed.

vi. Better taste.

vii. Improved stability.

viii. Suitable for controlled/sustained release actives.

ix. Allows high drug loading.

$\mathrm{x}$. Ability to provide advantages of liquid medication in the form of solid preparation.

xi. Cost effective.

xii. Rapid drug therapy intervention.

xiii. Best for patent with oesophageal problems and have difficulties of deglutition tablets.

xiv. High drug loading is possible.

xv. Have acceptable taste and pleasant mouth feeling.

xvi. Leave minimum residue. ${ }^{7}$

\section{Limitations of orodispersible tablets}

i. These tablets usually have insufficient mechanical strength i.e. hence, careful handling required.

ii. These tablets may leave unpleasant taste and/or grittiness in mouth if not formulated. ${ }^{8}$ 


\section{Ideal Properties of odts ${ }^{9-12}$}

The performance of ODTs depends on the technology used during their manufacture.

a. The necessary property of such tablets is the ability to disintegrate rapidly and disperse or dissolve in saliva, thereby obviating the need for water.

b. Various technologies have been developed that enable ODT to perform this unique function.

\section{An ideal ODT should meet the following criteria}

i. does not require water for oral administration yet disintegrates and dissolves in oral cavity within a few seconds

ii. has sufficient strength to withstand the rigors of the manufacturing process and post manufacturing handling allow high drug loading

iii. has a pleasant mouth feel

iv. is insensitive to environmental conditions such as humidity and temperature

v. is adaptable and amenable to existing processing and packaging machineries

vi. cost effective

\section{Methods used for preparation of odts}

\section{Melt granulation}

Melt granulation technique is a process by use of which pharmaceutical powders are efficiently agglomerated by a melt able binder. The advantage of this technique compared to a conventional granulation technique is that no water or organic solvents are required. Because there is no drying step involved, the process is less time consuming and uses less energy than wet granulation. It is a useful technique to increase the dissolution rate of poorly water-soluble drugs, such as griseofulvin. This approach to prepare ODT with sufficient mechanical integrity, involves the use of a hydrophilic waxy binder.

\section{Effervescent method}

rodispersible tablets are also prepared by effervescent method by mixing sodium bicarbonate and tartaric acid or citric acid of concentration $12 \%(\mathrm{w} / \mathrm{w})$ along with super disintegrants like pregelatinized starch, sodium starch glycolate, crospovidone, and croscarmellose. First, sodium bicarbonate and tartaric acid were preheated at a temperature of $80^{\circ} \mathrm{c}$ to remove absorbed/residual moisture and thoroughly mixed in the motor. Finally, the blends are compressed in the punch. ${ }^{13}$

\section{Cotton candy process}

In this process Shear form technology is used in the preparation of a matrix known as FLOSS, made from the combination of the recipients either alone or with the drugs. The fibrous nature of the floss is similar to the cotton-candy fibres. The floss is commonly made of saccharides such as sucrose, dextrose, lactose and fructose at temperatures ranging between $180-260^{\circ} \mathrm{F}$. Other polysaccharides such as polymaltodextrins and polydextrose can be converted into fibres at $30-40 \%$ lower temperature range.

\section{Direct compression}

It is the simplest and most cost effective tablet manufacturing technique for ODTs as they can be fabricated using conventional tablet manufacturing and packaging machinery and also due to availability of tableting excipients with improved flow, compressibility and disintegration properties, especially tablet disintegrants, effervescent agents and sugar based excipients. A type of disintegrant and its proportion are of prime importance. There are number of factors which affect disintegration like particle size distribution, contact angle, pore size distribution, tablet hardness, water absorption capacity and type and proportion of disintegrants. ${ }^{14}$

\section{Tablet molding}

Tablets produced by molding are solid dispersions. Physical form of the drug in the tablets depends whether and to what extent, it dissolves in the molten carrier. The drug can exist as discrete small particles or micro particles dispersed in the matrix. It can dissolve totally in the molten carrier to produce solid solution or dissolve partially in the molten carrier and the remaining particles stay un dissolved and dispersed in the matrix. Disintegration time, drug dissolution rate and mouth feel will depend on the type of dispersion or dissolution.

\section{Sublimation}

The key to rapid disintegration for orodispersible tablets is the presence of a porous structure in the tablet matrix. Conventional compressed tablets that contain highly water-soluble ingredients often fail to dissolve rapidly because of low porosity of the matrix. Hence, to produce porous matrix, volatile ingredients are used that are later subjected to a process of sublimation. Sublimation is a process in which water passes directly from solid state to vapour state without passing through liquid state. This process involves addition of some inert volatile substances like urea, urethane, naphthalene, camphor, menthol, etc to other excipients and the compression of blend into tablet. $^{15}$

\section{Phase transition}

MDTs were produced by compressing powder containing erythritol (melting point: $122^{\circ} \mathrm{C}$ ) and xylitol (melting point: $93-95^{\circ} \mathrm{C}$ ), and then heating at about $93^{\circ} \mathrm{C}$ for $15 \mathrm{~min}$ After heating, the median pore size of the tablets was increased and tablet hardness was also increased. The increase of tablet hardness associated with heating and storage did not depend on the crystal state of the lower melting point sugar alcohol. ${ }^{16}$

\section{Freeze drrying}

Freeze drying is the process in which water is sublimed from the product after it is frozen. This technique creates an amorphous porous structure that can dissolve or disperse rapidly. A typical procedure involved in the formulation of ODT using this technique is mentioned here. The active drug constituent is dissolved or dispersed in an aqueous solution of a carrier/polymer. The mixture is done by weight and poured in the walls of the preformed blister packs. The trays holding the blister packs are transfer through liquid nitrogen freezing tunnel to freeze the drug solution or dispersion. Then the frozen blister packages are placed in refrigerated cabinets to continue the freeze - drying process. After freeze-drying the aluminium foil backing is applied on a blister-sealing machine. Finally the blisters are packaged and shipped. The freeze-drying method has demonstrated improved absorption and increase in bioavailability of drug. The 
major disadvantages of lyophilisation method are that it is expensive method and time consuming; fragility makes conventional packaging unsuitable for these products and poor stability under stressed conditions.

\section{Mass-extrusion}

This technology involves softening the active blend using the solvent mixture of water-soluble polyethylene glycol and methanol and subsequent expulsion of softened mass through the extruder or syringe to get a cylinder of the product into even segments using heated blade to form tablet. The dried cylinder can also be used to coat granules for bitter drugs and thereby achieve taste masking. ${ }^{17}$

\section{Acknowledgements}

None.

\section{Conflict of interest}

The author declares that there is no conflict of interest.

\section{Reference}

1. Sastry SV, Nyshdham JR, Fix JA. Recent technological advances in oral drug delivery: A review. Pharmaceutical Science and Technology Today. 2000;3(4):138-145.

2. Seager H. Drug-delivery products and the Zydis fast-dissolving dosage form. Journal of Pharmacy and Pharmacology. 1998;50(4):375-382.

3. Rakesh RK. Orally Disintegrating Tablets novel tablets novel approach to drug delivery. Pharma Review. 2004;2(12):34-36.

4. Kraemer J1, Gajendran J, Guillot A, et al. Dissolution testing of orally disintegrating tablets. J Pharm Pharmacol. 2012;64(7):911-918.

5. Sreenivas SA. Orodispersible tablets: New- fangled drugdelivery systemA Review. Indian J.Pharm.Educ.Res. 2005;39(4):177-181.
6. Susjit S, Mishra B, Biswal P, Omprakash P, et al. Fast dissolving tablet: A potential drug delivery system. Drug Invention Today. 2010;2(2):130-133.

7. Tejvir K, Bhawandeep G, sandeep K. Mouth dissolving tablets: A novel approach to drug delivery. International Journal of Current Pharmaceutical Research. 2011;3(1):1-7.

8. Kolhe S, Chaudri P, More D. Development and evaluation of Melt-in mouth tablets by sublimation technique. International Journal of Pharmaceutical Studies and Research. 2011;2(1):165-176.

9. Sisodiya NS, Rathore GS, Sisodiya DS. Orodispersible tablets: a review. $J$ Global Pharma Tech. 2013;6(5):1-10.

10. Zydis YR. A novel fast dissolving dosage form. Man Chem. 1990;67:3637.

11. Pfister WR, Ghosh TK. Orally disintegrating tablets: products, technologies and development issues. Pharm Tech. 2005;29(10):136-150.

12. Patel PB. Fast dissolving drug delivery systems. Pharmainfo net. 2006;4(4):1-7.

13. Gupta A, Mishra k, Gupta V, Bansal P, et al. Mouth dissolving tablets: A review. International Journal of Pharmaceutical and Biological Archives. 2010;1:1-10.

14. Nand P, Vashisht A, Anand A, Suhma D. Mouth dissolving tablets: A novel drug delivery system. International Journal of Applied Biology and Pharmaceutical Technology. 2010;1(3):1-7.

15. Bikshathi D, Saikrishna K, Ashok kumar G, Sabitha G, et al. Fast dissolving tablets: An update. International Research Journal of Pharmacy. 2011;2(6):45-53.

16. Sonia D, Gurjit T, Pravin P. Mouth dissolving tablets: As a potential drug delivery system-A review. International Journal of Pharmaceutical Sciences Review and Research. 2011;11(1):85-94.

17. Debjit B, chiranjib B, Krishnkanth P, Chandrika R. Fast dissolving tablet: An overview. Journal of Chemical and Pharmaceutical Reasearch. 2009;1(1):163-177. 